\title{
Explosive Joining of Precious Metals
}

\author{
A Blatter and D A Peguiron \\ PX Tech, Bd. des Eplatures 46, CH-2304 La Chaux-de-Fonds, Switzerland.
}

\begin{abstract}
Though it might appear merely as a curiosity at first sight, explosives have already been employed for the integral welding of dissimilar metals to yield functional composites for use mainly in shipbuilding, off-shore and chemical installations. We have now explored the use of this technology for the joining of thin precious metal sheets with other metals. A variety of two-coloured semi-fabricates with potential ornamental applications in jewelry were produced. The bond strength and the formability of the various materials combinations were examined.
\end{abstract}

Explosive welding, simply stated, is a solid state welding process which uses a controlled explosive detonation to force two metals together at high pressure $(1-3)$. The resultant composite system is joined with a durable, metallurgical bond. The duration of the explosive welding event is so small that the reaction or heat affected zone between the constituent metals is microscopic. Unlike conventional methods such as hot-rolling or diffusion-bonding, explosive welding does not therefore rely on fusion but is rather considered a cold process. The obvious advantage is the possibility of joining dissimilar metals which would frequently be incompatible. Metals with largely different melting points can be combined, and the risk of the formation of brittle intermetallic compounds is significantly reduced.

We have employed explosive welding to produce gold-metal combinations for use as decorative multicolour items in jewelry or the watch industry. In this field of application, relatively thin gold claddings are the rule and a perfect surface finish after welding is mandatory. Such unusually stringent conditions require a very precise control of the process parameters. Furthermore, since explosive welding produces semifabricates in the form of ribbons or simple profiles, the joined composite must be sufficiently workable for the designer to transform it into the desired shape.

In this paper, after a short description of the underlying mechanism, we report on the explosive welding of various gold composites, and discuss the possibilities and limits of this unique technique. We focus on the bond strength and its development by cold deformation. Rolling, in particular, is a crucial process in view of cost-effective fabrication, because the sequence of explosive welding thick claddings and subsequent rolling to the desired size is cheaper than the direct cladding of thin coatings. This process, however, creates differential strains that may generate in the bonding area shear stresses high enough to cause delamination. An appropriate thermal treatment for stress relief may therefore be necessary between subsequent rolling passes to prevent premature failure. Annealing, however, normally modifies the interface structure and weakens the bond. The effect of the bimetallic nature of the composites on corrosion was also addressed.

\section{THE WELDING MECHANISM}

Figure 1 is a schematic presentation of the explosive welding process in its simplest configuration (for more details see references 2 and 3 ). One of the two metals to be welded (the base) is placed on a suitable support. The other metal (the flyer) is arranged parallel above the base at a certain stand-off distance. The flyer is charged with an appropriate explosive. For welding, the explosive is ignited on one side of the arrangement so that the moving detonation front drives the flyer down to collide with the base metal. The line of collision propagates behind the detonation front at the same velocity.

For successful welding, the collision conditions must be carefully chosen in order to provide a sufficiently strong impact while preventing excessive heating due to 'overimpact' $(3-5)$. The process is controlled by adjusting three major parameters. These are (i) the detonation velocity (typically 2000 - 3000 $\mathrm{m} / \mathrm{s}$ ), (ii) the ratio of the explosive mass to the flyer 


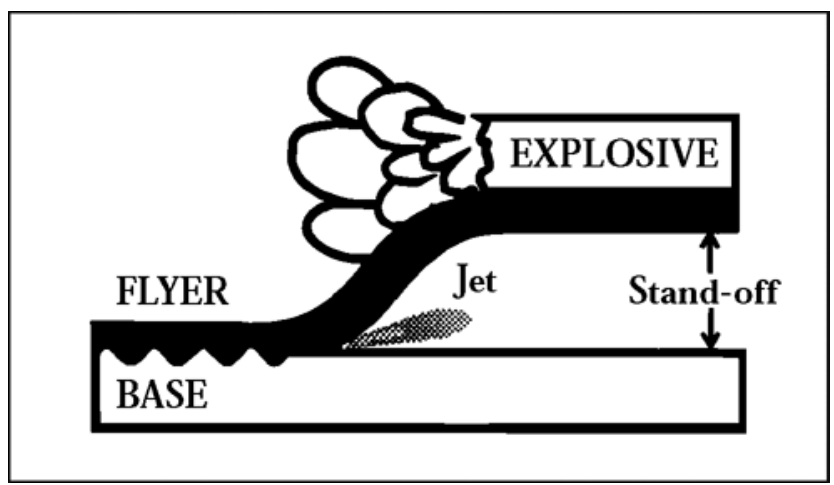

Figure 1 The explosive welding process.

mass $(\approx 1)$, and (iii) the acceleration distance corresponding to the stand-off distance (of the order of the flyer thickness). The flyer then strikes the base at a velocity of the order of several $100 \mathrm{~m} / \mathrm{s}$. Bonding is achieved when the atoms are pressed sufficiently close together (say $0.3 \mathrm{~nm}$ ) that the interatomic forces become attractive. Bonding thus requires a sufficiently strong impact of chemically clean surfaces.

The impact of the flyer with the base metal at this high velocity with some included angle of collapse creates a material jet (a spray of particles peeled off the two surfaces) in front of the collision. This jet scrubs away any superficial oxide layer and other contaminants to leave behind the chemically clean metal surfaces which are a prerequisite for the formation of a metallurgical bond.

Behind the line of collision, the high velocity impact creates a pressure of several GPa, which by far exceeds the material's elastic limits. This causes gross plastic deformation and eventual joining. In fact, the materials exhibit fluid-like behaviour in the compressed zone (the viscosity of steel, for example, is in the range of $10^{4}-10^{5} \mathrm{~Pa}$ under these conditions) which is reflected by a wavy interface characteristic of explosive welding.

\section{EXPERIMENTAL PROCEDURES}

A system of the type shown in Figure 1 was used to weld $18 \mathrm{ct}$ gold sheets of standard compositions $2 \mathrm{~N}$ to $5 \mathrm{~N}$ inclusive to various base metals including gold alloys (2N - 5N, white golds), silver, low-carbon austenitic stainless steel (AISI 316L), aluminum, and titanium. The gold claddings were 0.4 - $3 \mathrm{~mm}$ thick, up to $2 \mathrm{~m}$ in length, and typically $7 \mathrm{~cm}$ in width. Due to the cleaning action of the material jet, no particular pretreatment of the surfaces was necessary - degreasing with an organic solvent was sufficient. A specially designed support enabled the cladding of near flat-top profiles, as will be discussed later. An explosive with a detonation velocity of approximately $2500 \mathrm{~m} / \mathrm{s}$ (depending on its thickness) and a density of $0.7 \mathrm{~g} / \mathrm{cm}^{3}$ was employed for most experiments.

In addition to the standard system (Figure 1), we placed a $3-10 \mathrm{~mm}$ thick polyethylene buffer layer between the explosive and the flyer. The purpose of this buffer was to protect the cladding from damage due to the impact of detonation products as well as to moderate the enormous detonation forces. The plastic buffer damps out local pressure peaks which are related to the granular consistency of the explosive, and it adds additional mass to the flyer to reduce its acceleration. This is imperative for thin flyers to prevent their disintegration due to excessive acceleration. In addition, the buffer serves as a convenient support to which the thin (and hence flexible) flyers can be glued to ensure a constant stand-off distance.

The bond interfaces of the resulting composites were characterized by cross-sectional microscopy and energy-dispersive $\mathrm{x}$-ray analysis. The bond strength was checked by various deformation tests. Cold rolling annealing cycles were elaborated for the various metal combinations.

\section{RESULTS}

\section{Gold - precious metals}

The explosive welding of yellow gold with other gold alloys or silver resulted in a tough bond as strong as the constituent metals in an extended range of processing parameters. This easy joining is favoured by the mutual solid solubility of the two materials, which means the absence of a risk for the formation of brittle compounds. Metallurgical sections in the direction of the detonation rendered visible a regular sine-wave type of interface pattern without inclusions or pores (Figure 2) while transverse cuts revealed a straight transition line.

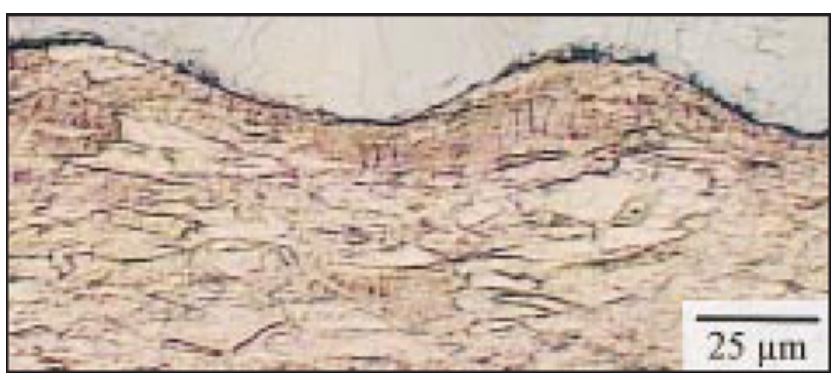

Figure 2 Micrograph showing the regular wavy yellow gold white gold interface. 
The composites could be deformed and rolled to almost any degree without substantial loss of bond strength. Also, annealing for stress relief did not pose particular problems. Such favourable behaviour is related to the ductility, and the mechanical as well as thermal similarity of the constituent metals.

\section{Gold - stainless steel (AISI 316L)}

The explosive cladding of $<0.2 \mathrm{~mm}$ thick gold sheets for the lining of nickel-chromium steel autoclaves has already been demonstrated (6). We indeed obtained a perfect integral bonding between gold and the stainless steel, as verified by ultrasonic inspection. Figure 3 displays the typical wavy interface of a composite welded under conditions that resulted in highest strength. The waves appear to be slightly turbulent with some melt pockets localized at their crests.

For a qualitative test of bond strength and formability, a gold - steel $(0.4 \mathrm{~mm}-1 \mathrm{~mm})$ ribbon was rolled $20 \%$. From this ribbon, small test specimens were punched and subjected to various deformations. No debonding occurred upon hammering, twisting, plying or machining.

There is, however, a practical limit to the acceptable degree of deformation due to the work hardening of the steel. A rolling reduction of $40 \%$, for instance, raises the hardness of the steel to $\mathrm{HV} 320$, which generally is far too high for further processing. A stress relief is not feasible here because the high annealing temperature required to soften the steel would melt the gold alloy.

Figure 4 displays some potential products (twocolour links for a watch strap) made from explosionclad ribbons and simple profiles, respectively. The simultaneous cladding of several profiles - each $3 \mathrm{~mm}$ thick, $7 \mathrm{~mm}$ wide and up to $2 \mathrm{~m}$ long - was accomplished using a specially devised approach. The profiles were placed in parallel and separated from each other by a small distance, in pre-machined grooves on a plastic support. The grooves served to suppress

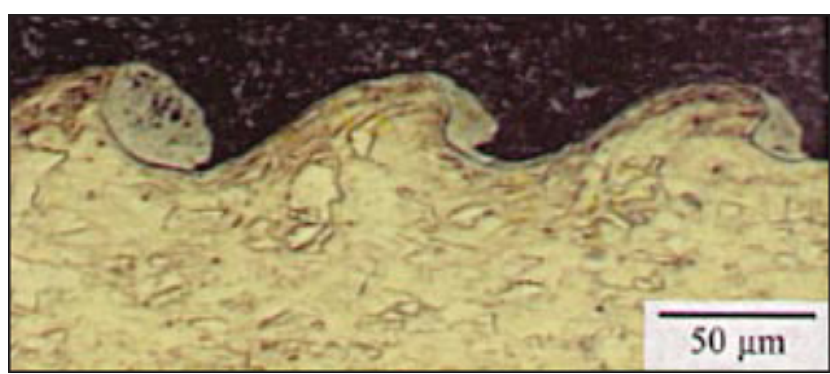

Figure 3 Micrograph of the gold - stainless steel interface showing slightly turbulent waves with localized melt pockets.

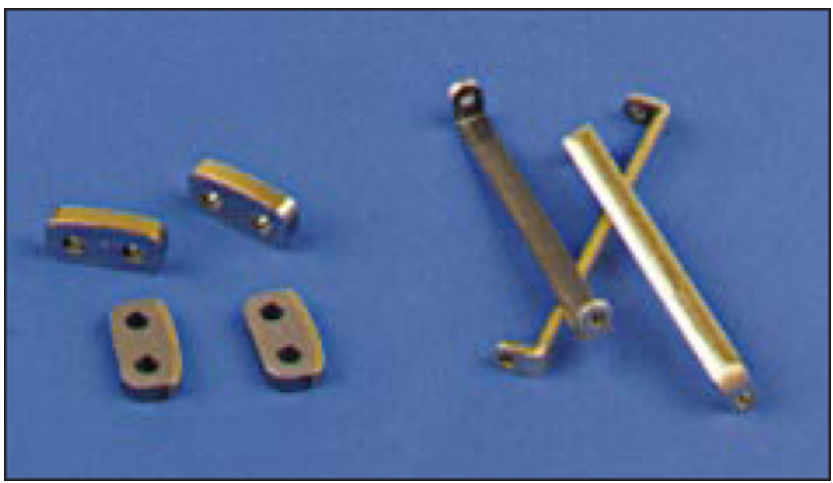

Figure 4 Two-colour gold - steel specimens fabricated from explosion welded bands and bars, respectively.

transverse deformation during impact of the gold flyer. One single gold sheet was fixed $2 \mathrm{~mm}$ above the assembly and loaded with the explosive. Upon impact, the edges of the bars sheared off the flyer sheet to produce clad profiles and separated gold stripes. Modest rectification and side-lapping of the clad profiles were necessary because the enormous impact forces led to a slight deformation of their edges.

\section{Gold - titanium}

Impact velocities somewhat higher than usual were required to achieve a good metallurgical bond between gold and titanium. In contrast to the other material combinations, as seen in Figure 5, the interface here remained essentially flat and the presence of some localized impurities was observed.

For a stringent test of the bond strength, a specimen of length $10 \mathrm{~cm}$ was cut from the explosionwelded ribbon and then twisted about its longitudinal axis in torsion equipment. Table 1 gives the number of $360^{\circ}$ left and right turns at which failure first occurred.

The composites were rolled to various degrees; a size reduction greater than $85 \%$ being readily achieved without intermediate annealing between consecutive rolling passes. Annealing conditions applicable to both

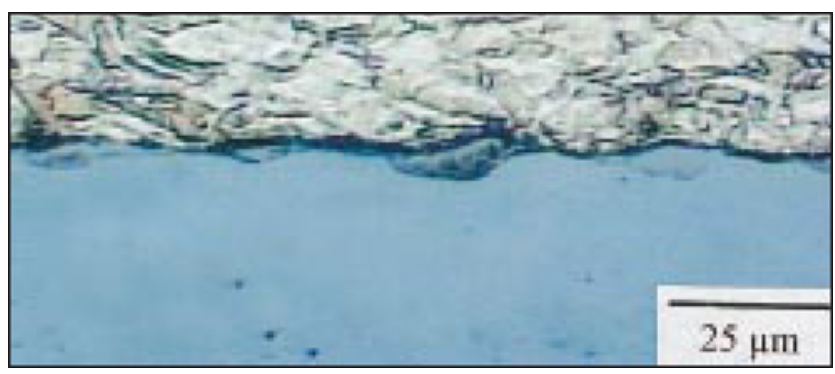

Figure 5 Micrograph displaying the flat interface of explosion welded gold-titanium. 
Table 1 Hardness and number of twists to failure of gold-titanium and silver-aluminium specimens, after explosion welding and at various stages of a subsequent rolling-annealing sequence.

\begin{tabular}{|c|c|c|c|c|c|}
\hline & & as welded & and rolled $(50 \%)$ & and annealed & and rolled $(50 \%)$ \\
\hline & $\mathrm{Au}$ & 200 & 240 & 130 & 240 \\
\hline Hardness $\mathrm{HV}_{0.5}$ & $\mathrm{Ti}$ & 175 & 250 & 165 & 245 \\
\hline \multirow[t]{2}{*}{ (MPa) } & $\mathrm{Ag}$ & 75 & 90 & 50 & 90 \\
\hline & $\mathrm{Al}$ & 35 & 40 & 20 & 40 \\
\hline Torsion & $\mathrm{Au}-\mathrm{Ti}$ & $>30$ & $>30$ & 20 & 5 \\
\hline (cycles) & $\mathrm{Ag}-\mathrm{Al}$ & $\approx 10$ & $\approx 2$ & $\approx 10$ & $\approx 1$ \\
\hline
\end{tabular}

Annealing conditions were: $650^{\circ} \mathrm{C}, 30 \mathrm{~min}$ in vacuum for $\mathrm{Au}$ - $\mathrm{Ti}_{\mathrm{i}}$ and, respectively, $350^{\circ} \mathrm{C}, 60 \mathrm{~min}$ for $\mathrm{Ag}$-Al. Note that failure normally was by fracture of the specimen; only after the first annealing did failure occur by deboning in the case of the gold-titanium composite.

gold and titanium enabled the elimination of the work hardening. Each annealing step, however, progressively reduced the bond strength as is apparent from Table 1.

Complications in thermal softening arose due to the reactivity of titanium and the strong thermodynamic tendency for the formation of intermetallic $\mathrm{Au}-\mathrm{Ti}$ compounds. Compound formation requires elemental interdiffusion and this increases exponentially with temperature. Moreover, gold is known to be a fast diffuser in titanium (7). Therefore, annealing must be done as quickly as possible, and at the minimum temperature required for softening. Annealing at $650^{\circ} \mathrm{C}$ for $30 \mathrm{~min}$ was found to be a good compromise. All heat treatment was performed in high-vacuum $\left(<10^{-3} \mathrm{~Pa}\right)$ to avoid oxidation, although an inert argon atmosphere also proved to be sufficient.

Remarkably, the weakening of the bond strength upon annealing was found to depend on the amount of cold work prior to heat treatment. Pre-rolling of $50 \%$ resulted in immediate delamination after one single torsion cycle whereas samples rolled $85 \%$ before annealing resisted 5 torsion cycles. A possible explanation for this unusual behaviour might be that the stronger the deformation the more likely is the cracking and dispersion of interfacial intermetallic layers. This would produce new virgin metallic surfaces which partially cold-weld under further straining. Whatever the cause may be, the bond of a material rolled 50\% and subsequently annealed remained sufficiently strong for the deep drawing of capsules as is evident in Figure 6.

\section{Gold - aluminium}

In view of jewelry applications, the combination of precious metals with aluminium might be particularly

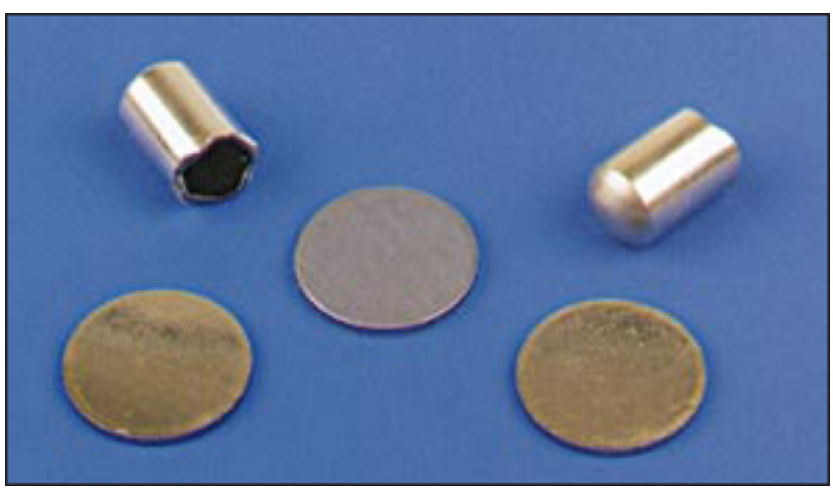

Figure 6 Bimetal capsules drawn from explosion welded goldtitanium ribbons.

attractive as the aluminium offers the possibility of later coloration by anodization. The palette of colours with this process is almost unlimited. For anodization, the noble metal must be protected from dissolution, for instance by applying a bath-resisting paint.

The explosive welding of gold with aluminium, however, caused substantial melting and elemental intermixing at the bonding surfaces as is manifested by the formation of a distinct, stunningly purple interphase region of width approximately $20 \mu \mathrm{m}$ (Figure 7). The interphase was identified as $\mathrm{Al}_{2} \mathrm{Au}$ by energy-dispersive $\mathrm{x}$-ray analysis. This intermetallic compound, also known as purple gold, is inherently brittle and limits the strength of the weld. Plying caused the cracking of the compound layer as was clearly audible. Re-bending eventually resulted in the separation of the two metals.

It is possible indeed to reduce the thermal load of the interface by using a lower explosive charge. However, given the low melting point of aluminium and its reactivity with gold, it may be impossible to 
suppress compound formation even at the lowest charge required to generate the necessary pressure for bonding.

A better approach is the use of an intermediate layer that is compatible with both gold and aluminium. Silver is a promising candidate; it bonds easily with gold as discussed above and it exhibits extended solid solubility with aluminium.

Explosive welding of silver and aluminium did indeed produce exceptionally good bonding (Table 1). The resulting specimens were malleable and deformable to almost any extent. Annealing, though not really necessary because of only marginal work hardening, did not cause any embrittlement of the interface. When excessively tortured, failure occurred by fracture of the specimen rather than by de-bonding.

\section{DISCUSSION}

In explosive welding, a good bond is characterized by an abrupt transition from one material to the other as well as the absence of melt pockets, pores or inclusions. If their presence cannot be prevented they should preferably be localized along the interface such as for gold-titanium (Figure 5).

Often, the presence of a wavy interface is taken to imply a strong bond as it indicates that hydrodynamic conditions favourable for metallurgical bonding were prevailing during the process. Usually, the interface changes from planar to regular wavy to turbulent with increasing impact velocity, ie increasing explosive charge and stand-off distance. Even higher velocities will cause thorough melting of the interface region. This is what happened with the gold - aluminum samples (Figure 7).

In the case of gold-titanium, it was not possible to achieve a wavy interface in spite of a broad variation of the process parameters. A metallurgical bond with excellent strength was nevertheless achieved. In fact, the development of the interface structure depends not only on the collision conditions, but also on the characteristics of the material jet. When two materials of identical density are projected together, the jet is ejected along the centerline between the two materials. A regular sine-wave interface develops (Figure 2) with its amplitude and wavelength being related according to the hydrodynamic stability criterion of Karman (8). At largely differing densities, as for gold and titanium, however, the jet inclines towards the higher density material (9). Impingement on the high density material will obstruct free jetting so that the collision

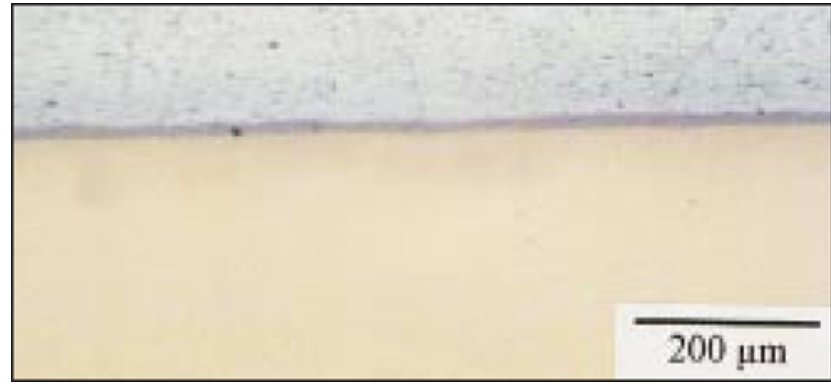

Figure 7 Micrograph of explosion welded gold-aluminum, showing the $\mathrm{Al}_{2} \mathrm{Au}$ transition layer.

front may overwhelm part of it. Particles from the jet are consequently trapped and dispersed at the interface. The intermetallic inclusions in the goldtitanium interface are a result of this mechanism rather than a diffusion phase precipitated at equilibrium.

Bimetals are susceptible to galvanic corrosion if their constituent metals have different electrochemical potentials. In gold-steel composites, the difference in potential being $230 \mathrm{mV}-300 \mathrm{mV}$, the galvanic contribution to the overall corrosion may lead not only to accelerated de-bonding, but also raise the release of nickel ions. This latter aspect is of uppermost importance in jewelry applications with regard to nickel allergy*

We measured the nickel release of explosion welded gold-steel specimens following the procedure given for Project of European Standard prEN 1811. Briefly, test specimens were immersed in artificial sweat and stored at $30^{\circ} \mathrm{C}$ for 7 days. The amount of nickel released into the sweat was afterwards determined by inductively coupled plasma spectroscopy (ICP). The result is expressed in units normalized to time and surface of the test specimen.

The nickel release of explosion welded specimens was substantially higher as compared with conventionally diffusion brazed material. Values in the range $10-20 \mu \mathrm{g} \mathrm{cm}^{-2}$ week ${ }^{-1}$ were measured. Much lower release rates were obtained when, in imitation of conventional brazing, a filler metal powder was diffused into the steel surface prior to explosion welding. With a $\mathrm{PdAg}$-based filler, the nickel release reduced to $2 \mu \mathrm{g} \mathrm{cm}^{-2}$ week $^{-1}$. This value, however, is at best comparable with conventionally brazed material and the bonding interface still suffers from accelerated localized corrosion.

\footnotetext{
* Annex I to European Directive $76.769 / \mathrm{EEC}$ imposes a limit of $0.5 \mu \mathrm{g}$ $\mathrm{cm}^{-2}$ week ${ }^{-1}$ to the tolerable level of nickel release for products coming into direct and prolonged contact with the skin.
} 
In contrast to the gold-steel composites, no particular problems related to corrosion were noticed with the other material combinations.

\section{CONCLUSIONS}

We have adapted the technique of explosive welding to produce precious claddings on a variety of metals. Such semi-fabricates may provide novel ornamental material for use in jewelry items, medallions, spectacle frames or watch straps, just to mention a few. In order to pass as a gold-metal product, the final thickness of the gold cladding must be at least $0.2 \mathrm{~mm}$. Whilst being rather thin for explosive welding, claddings of this thickness having a comparable quality when obtained by alternative methods such as electroplating or plasma spraying are the exception rather than the rule.

Among the benefits of this technique is the potential for joining dissimilar metals which otherwise would be incompatible or difficult to weld. A high quality, metallurgical bond results when melting, and the formation of brittle intermetallic compounds are prevented by a proper control of the process parameters. Compound formation was inevitable in the joining of gold-aluminium, resulting in brittle specimens. The problem can be circumvented by inserting a silver interlayer.

Heat treatments, which may be necessary to remove the effects of strain hardening, may also cause bond deterioration due to compound formation. Annealing conditions must then be chosen so as to give the best compromise between hardness and bond strength. In some cases such as in gold-steel, thermal softening is impossible and this will limit the practicable amount of cold working.

\section{ACKNOWLEDGEMENTS}

We are indebted to L. Reclaru (PX Tech) for the corrosion tests. The explosion welding was done in collaboration with SM Thun and we wish to acknowledge in particular the indispensable assistance given by $\mathrm{D}$. Meyer.

\section{ABOUT THE AUTHORS}

Dr Andreas Blatter is a lecturer in Applied Physics at the University of Berne and head of the R\&D Department at PX Tech. His research interest has been in non-equilibrium processing and metastable materials. The core domain of PX Tech is the metallurgy, in particular for the watch, jewellery and medical sector. This includes notably the development of precious and special alloys, related technologies, and materials characterization, as well as corrosion and biocompatibility studies

David Peguiron received his degree in metallurgy from the University of Neuchätel. He was working on shape memory alloys and iron-aluminides for turbine applications. Three years ago he joined PX Tech, where he has been in charge of metallurgical developments.

\section{REFERENCES}

1 'Shock Waves for Industrial Applications', ed. L.E. Murr, Noyes Publications, Park Ridge, N.J., USA, 1988

2 B. Crossland, 'Explosive Welding of Metals and its Application', ed. B. Crossland, Clarendon Press, Oxford, UK, 1982

3 'Explosive Welding, Forming and Compaction', ed. T.Z. Blazynski, Applied Science Publisher, London, 1983

4 'Fundamentals of Shaped Charges', W.P. Walker and J.A. Zukas, John Wiley and Sons, New York, 1989

5 H. Wolf, Umformtechnik, Zwickau, 1984, 18, 245

6 G. Bechtold, I. Michael and R. Prümmer, Gold Butll, 1977, 10, 34

7 A.D. LeClaire, J. Nucl. Mater, 1978, 69/70, 70

8 G.R. Cowan, O.R. Bergman and A.H. Holtzman, Met. Trans, 1971, 2, 3145

9 'A Metallurgical Investigation of Explosion Welding', W. Lucas, Thesis, Queen's University of Belfast, UK, 1970 